\title{
Statement of Purpose
}

LEARNing Landscapes ${ }^{\mathrm{TM}}$ Journal is an open access, peer-reviewed, online education journal supported by LEARN (Leading English Education and Resource Network).

Published in the spring and autumn of each year, it attempts to make links between theory and practice and is built upon the principles of partnership, collaboration, inclusion, and attention to multiple perspectives and voices. The material in each publication attempts to share and showcase leading educational ideas, research, and practices in Quebec, and beyond, by welcoming articles, interviews, visual representations, arts-informed work, and multimedia texts to inspire teachers, administrators, and other educators to reflect upon and develop innovative possibilities within their own practices. 